\title{
Exploration of regiospecificity phenomenon in $[2+3]$ cycloaddition reactions between arylnitrones and trans-substituted nitroethenes on the basis of the reactivity indices theory
}

\author{
Radomir Jasiński*
}

Institute of Organic Chemistry and Technology, Cracow University of Technology, Warszawska 24, 31 155 Kraków

\begin{tabular}{|c|c|}
\hline ART I CLE I N FO & A B S T RA C T \\
\hline $\begin{array}{l}\text { Article history: } \\
\text { Received May } 30,2012 \\
\text { Received in Revised form } \\
\text { July } 31,2012 \\
\text { Accepted } 1 \text { August } 2012 \\
\text { Available online }\end{array}$ & $\begin{array}{l}\text { Analysis of global electrophilicity and nucleophilicity power of the addends indicate polar } \\
\text { character of }[2+3] \text { cycloaddition reactions between arylnitrones and trans-substituted } \\
\text { nitroethenes. The regioselectivity of these reactions is determined by nucleophilic attack of } \\
\text { oxygen atom from nitrone on activated } \beta \text {-position of nitroalkene. Interaction of this type leads } \\
\text { to 4-nitroisoxazolidines, which are the only reaction products. }\end{array}$ \\
\hline
\end{tabular}

(C) 2012 Growing Science Ltd. All rights reserved.

\section{Introduction}

[2+3] Cycloaddition reactions of nitrones with conjugated nitroalkenes are the most universal methods for preparation of nitroisoxazolidines, which are effective synthons in syntheses of aminoacids, alkaloids and $\beta$-lactams ${ }^{1,2}$. It is interesting, that these reactions exhibit extremely high regioselectivity. [2+3] Cycloaddition of nitrones with simple $\alpha, \beta$-disubstituted ethenes almost always leads to mixtures of regioisomeric adducts. On the other hand, [2+3] cycloaddition of arylnitrones with trans-substituted nitroethenes usually proceeds in a regiospecific way (e.g., the reaction of arylnitrones with (E)-1-nitroprop-1-ene ${ }^{3-5}$, (E)- $\beta$-nitrostyrene ${ }^{6},(\mathrm{E})-2-$ chloro-1-nitroethene $^{7}$ and (E)3,3,3-trichloro-1-nitroprop-1-ene $\left.{ }^{4,7}\right)$. All of these reactions occur with full regiocontrol and lead to the

* Corresponding author.

E-mail addresses: radomir@chemia.pk.edu.pl (R. Jasiński) 
corresponding 4-nitroisoxazolidines as the only reaction products (Scheme 1, Table 1), regardless of the nature of substituent in $\beta$-position of the nitroethenyl moiety (Table 2). In the present work we decided to explain this phenomenon on the grounds of electrophilicity and nucleophilicity indices theory. Recently, similar approach was used successfully to explain the regiochemical aspects of nitrones $[2+3]$ cycloaddition with several dipolarophiles ${ }^{8,9}$.

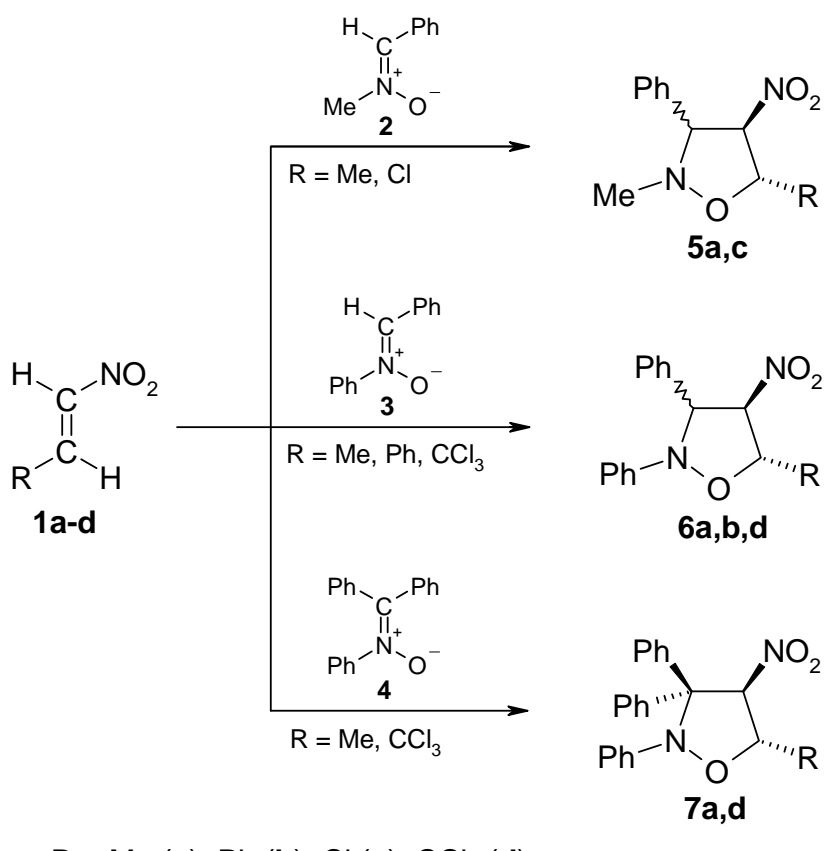

$\mathrm{R}=\mathrm{Me}(\mathbf{a}), \mathrm{Ph}(\mathbf{b}), \mathrm{Cl}(\mathbf{c}), \mathrm{CCl}_{3}(\mathbf{d})$

Scheme 1. Regioselectivity of [2+3] cycloaddition reactions between nitroalkenes 1a-d and nitrones 2-4.

Table 1. Experimental conditions and yields for model reactions.

\begin{tabular}{|c|c|c|c|c|c|}
\hline \multicolumn{2}{|l|}{ Addents } & \multirow[t]{2}{*}{ Conditions } & \multirow{2}{*}{$\begin{array}{c}\text { Yields } \\
{[\%]}\end{array}$} & \multirow{2}{*}{$\begin{array}{l}\text { Regioisomer ratio } \\
\text { [4-nitro]:[5-nitro] }\end{array}$} & \multirow[t]{2}{*}{ Ref. } \\
\hline Nitroalkene & Nitrone & & & & \\
\hline $1 \mathbf{a}$ & 2 & $80^{\circ} \mathrm{C}$, benzene, $3 \mathrm{~h}$ & 94 & $1: 0$ & 3 \\
\hline $1 \mathbf{a}$ & 3 & $25^{\circ} \mathrm{C}$, toluene, $24 \mathrm{~h}$ & 97 & $1: 0$ & 4 \\
\hline $1 \mathbf{a}$ & 4 & $25^{\circ} \mathrm{C}$, solvent free, $0,25 \mathrm{~h}$ & 96 & $1: 0$ & 3 \\
\hline $1 b$ & 3 & $80^{\circ} \mathrm{C}$, toluene, $24 \mathrm{~h}$ & 92 & $1: 0$ & 6 \\
\hline 1c & 2 & $25^{\circ} \mathrm{C}$, benzene, $24 \mathrm{~h}$ & 41 & $1: 0$ & 7 \\
\hline 1d & 3 & $25^{\circ} \mathrm{C}$, toluene, $24 \mathrm{~h}$ & 94 & $1: 0$ & 4 \\
\hline 1d & 4 & $25^{\circ} \mathrm{C}$, toluene, $12 \mathrm{~h}$ & 98 & $1: 0$ & 6 \\
\hline
\end{tabular}

\section{Results and Discussion}

The global (electronic potential $\mu$, electrophilicity power $\omega$, nucleophilicity $N$ ) and local (electrophilicity $\omega_{\mathrm{k}}$, nucleophilicity $\mathrm{N}_{\mathrm{k}}$ ) reactivity indices for example reactants (1-2) were estimated according to the equations recommended by Parr $^{10}$ and Domingo (for details see next section). Electrophilicity scale was built and validated by Domingo group ${ }^{11}$ based on the B3LYP/6-31g(d) calculations. This model was adopted for most reaction systems ${ }^{9}$. Therefore, the quantum chemical calculations were performed using B3LYP/6-31g(d) theoretical level ${ }^{12}$. The results are collected in 
Table 2. Global and local electronic properties of nitroalkenes 1a-d and nitrones $\mathbf{2 - 4}$

\begin{tabular}{|c|c|c|c|c|c|c|c|c|c|c|}
\hline & \multirow[b]{2}{*}{1} & \multirow[b]{2}{*}{$\mathrm{R}$} & \multirow[b]{2}{*}{$\sigma_{\mathrm{R}}$} & \multicolumn{3}{|c|}{ Global properties } & \multicolumn{4}{|c|}{ Local properties } \\
\hline & & & & $\begin{array}{c}\mu \\
\text { (a.u.) }\end{array}$ & $\begin{array}{c}\omega \\
(\mathrm{eV})\end{array}$ & $\begin{array}{c}\mathrm{N} \\
(\mathrm{eV})\end{array}$ & $\begin{array}{c}\omega_{\alpha} \\
(\mathrm{eV})\end{array}$ & $\begin{array}{c}\omega_{\beta} \\
(\mathrm{eV})\end{array}$ & $\begin{array}{c}\mathrm{N}_{\mathrm{C}} \\
(\mathrm{eV})\end{array}$ & $\begin{array}{c}\mathrm{N}_{\mathrm{O}} \\
(\mathrm{eV}) \\
\end{array}$ \\
\hline $1 \mathrm{a}$ & $\mathrm{Me}$ & & -0.17 & -0.1867 & 2.36 & & 0.05 & 0.25 & & \\
\hline $1 b$ & $\mathrm{Ph}$ & & $-0,01$ & -0.1760 & 2.66 & & 0.10 & 0.23 & & \\
\hline 1c & $\mathrm{Cl}$ & & 0.23 & -0.2053 & 2.89 & & 0.09 & 0.34 & & \\
\hline 1d & $\mathrm{CCl}_{3}$ & & 0.45 & -0.2147 & 3.27 & & 0.15 & 0.34 & & \\
\hline 2 & 2 & - & 3 & -0.1244 & 1.35 & 3.62 & & & 0.29 & 0.63 \\
\hline 3 & - & & - & -0.1312 & 1.67 & 3.64 & & & 0.28 & 0.57 \\
\hline 4 & - & & - & -0.1256 & 1.56 & 3.83 & & & 0.31 & 0.60 \\
\hline
\end{tabular}

It has been found, that the nitrones 2-4 show weaker electrophilic character than the nitroethenes 1a-d. Their electronic potential $(\mu)$ equals $-0.1244 \div-0.1256$ a.u., whereas that of the nitroalkenes 1a-d is only $-0.1867 \div-0.2147$. This indicates, that in the reactions studied, the charge should be transferred from nitrone to nitroalkene. Analysis of global electrophilicity indices $(\omega)$ leads to similar conclusion.

In particular, global electrophilicity $(\omega)$ of 1-nitroprop-1-ene (1a) is equal $2.36 \mathrm{eV}$. Replacement of methyl group with phenyl ring increases $\omega$ value to $2.66 \mathrm{eV}$. Further increase of the nitroalkene electrophilicity takes place after introduction electron withdrawing substituents (e.g., $\mathrm{Cl}, \mathrm{CCl}_{3}$ ) into the $\beta$-position of nitrovinyl moiety. In consequence, 3,3,3-trichloro-1-nitroprop-1-ene $(\omega=3.27 \mathrm{eV})$ is the strongest electrophile in this study.

Table 3. Electrophilicity difference $(\Delta \omega)$ for the nitroalkene/nitrone pairs

\begin{tabular}{llc}
\hline Addents & & $\Delta \omega$ \\
\cline { 1 - 2 } Nitroalkene & Nitrone & {$[\mathrm{eV}]$} \\
\hline 1a & $\mathbf{2}$ & 1.01 \\
1a & $\mathbf{3}$ & 0.69 \\
1a & $\mathbf{4}$ & 0.80 \\
1b & $\mathbf{3}$ & 0.99 \\
1c & $\mathbf{2}$ & 1.54 \\
1d & $\mathbf{3}$ & 1.60 \\
1d & $\mathbf{4}$ & 1.71 \\
\hline
\end{tabular}

For comparison, global electrophilicity $(\omega)$ of the nitrone (2) equals $1.35 \mathrm{eV}$. Hence in terms of the Domingo terminology ${ }^{8}, \mathbf{2}$ is a moderate electrophile. The $\omega$ values of the nitrones $\mathbf{3}$ and $\mathbf{4}$ are slightly higher (1.67 eV and $1.56 \mathrm{eV}$ respectively), so they are stronger electrophiles. This is what we expected due to the nucleophilic character of $>C=N(O)$ - moiety, electrophilicity of the nitrones $\mathbf{2 - 4}$ are lower than those of the nitroalkenes 1a-d. In the reactions studied they are nucleophiles (global nucleophilicty $\mathrm{N}>3.5 \mathrm{eV}$ ).

The electrophilicity difference $(\Delta \omega)$ of the analysed reagent pairs (Scheme 1) is in the range from 0.69 to 1.71 (Table 3). Therefore, the reactions can be considered as polar cycloadditions ${ }^{8}$. According to the Domingo concept ${ }^{8,13}$, the regioselectivity of such reactions may be forecasted using local electrophilicity $\left(\omega_{\mathrm{k}}\right)$ and nucleophilicity $\left(\mathrm{N}_{\mathrm{k}}\right)$ indices. According to this approach, most favorable interaction takes place between most nucleophilic and most electrophilic centers.

The values of $\omega_{\mathrm{k}}$ obtained for the nitroalkenes 1a-d (Table 2) indicate, that $\beta$-position of the nitrovinyl moiety is the most electrophilic site, therefore, it should be the preferred position for 
nucleophilic attack. In particular, for less electrophilic 1-nitroprop-1-ene (1a) $\omega_{\beta}=0.23 \mathrm{eV}$, whereas for more electrophilic 3,3,3-trichloro-1-nitroprop-1-ene (1d) $\omega_{\beta}=0.34 \mathrm{eV}$. On the other hand, the $\mathrm{N}_{\mathrm{k}}$ indices indicate that in the nitrones 2-4, the oxygen atom of $>\mathrm{C}=\mathrm{N}(\mathrm{O})$ - moiety is the most nucleophilic site $\left(\mathrm{N}_{\mathrm{O}}=0.57 \div 0.63 \mathrm{eV}\right)$. Hence, the reaction course should be controlled by the attack of one of the nucleophilic sites in the nitrone on the electrophilic site localized on the atom $\mathrm{C}_{\beta}$ in nitrovinyl group of the corresponding nitroalkene. (Scheme 1). Interactions of this type lead to 4nitroisoxazolidines.

\section{Conclusions}

Analysis of global electronic properties of the addends indicate polar character of [2+3] cycloaddition reactions between arylnitrones and trans-substituted nitroethenes. This is consistent with the kinetic studies ${ }^{3,7}$. The regioselectivity of these reaction is determined by nucleophilic attack of the oxygen atom of $>\mathrm{C}=\mathrm{N}(\mathrm{O})$ - nitrone moiety on activated $\beta$-position of nitroalkene. Interaction of this type leads to 4-nitroisoxazolidines as the only reaction products ${ }^{3-7}$.

\section{Acknowledgements}

Generous allocation of computing time by the regional computer center "Cyfronet" in Cracow (grant MNiI/SGI2800/PK/053/2003) and financial support from the Polish Ministry of Science and Higher Education (grant C-2/175/DS/2012) are gratefully acknowledged.

\section{Computational details}

The quantum-chemical calculations were performed on a SGI-Altix-3700 computer in the Cracow Computing Center "CYFRONET". Hybrid B3LYP functional and 6-31G(d) basis set included within GAUSSIAN 2009 software $^{12}$ were applied. For structure optimization of the reactants FOPT procedure was applied. Calculations of all critical structures were performed for the temperature $\mathrm{T}=298 \mathrm{~K}$ and pressure $\mathrm{p}=1 \mathrm{~atm}$. The global reactivity indexes were estimated according to equations recommended by Parr and Yang $^{10}$ and Domingo ${ }^{8}$. In particular, the electronic chemical potentials $(\mu)$ and chemical hardness $(\eta)$ of the reactants 1 and 2 were evaluated in terms of the one electron energies of FMO:

$\mu=\left(\mathrm{E}_{\mathrm{HOMO}}+\mathrm{E}_{\mathrm{LUMO}}\right) / 2 ; \quad \eta=\mathrm{E}_{\mathrm{LUMO}}-\mathrm{E}_{\mathrm{HOMO}}$

The values of $\mu$ and $\eta$ were then used for calculation of the global electrophilicity $(\omega)$ according to the formula:

$\omega=\mu^{2} / 2 \eta$

The global nucleophilicity $(\mathrm{N})$ of nitrones $\mathbf{1 a - d}$ was calculated as the difference ${ }^{12}$ :

$\mathrm{N}=\mathrm{E}_{\mathrm{HOMO}}$ (nitrone) $-\mathrm{E}_{\mathrm{HOMO}(\text { tetracyanoethene) }}$

The local electrophilicity $\left(\omega_{\mathrm{k}}\right)^{8}$ condensed to atom $k$ was calculated by projecting the index $\omega$ onto reaction centre $k$ in the molecule by using Fukui function $\mathrm{f}^{+}$, whereas the local nucleophilicity $\left(\mathrm{N}_{\mathrm{k}}\right)^{13}$ condensed to atom $k$ was calculated using global nucleophilicity $\mathrm{N}$ and Fukui function $\mathrm{f}_{\mathrm{k}}$ according to the formulas:

$\omega_{\mathrm{k}}=\mathrm{f}_{\mathrm{k}}^{+} \omega ; \quad \mathrm{N}_{\mathrm{k}}=\mathrm{f}_{\mathrm{k}} \mathrm{N}$ 
According to Contreras observations ${ }^{14}$, Fukui $\mathrm{f}^{+}{ }_{\mathrm{k}}$ is represented by the square of the suitable LUMO coefficient $(\mathrm{C})$, whereas $\mathrm{f}_{\mathrm{k}}$ by the square of the suitable HOMO coefficient:

$\mathrm{f}_{\mathrm{k}}^{+}=\mathrm{C}_{\mathrm{LUMO}}{ }^{2} ; \quad \mathrm{f}_{\mathrm{k}}=\mathrm{C}_{\mathrm{HOMO}}{ }^{2}$

The results are collected in Table 2 .

\section{References}

1 Barański A., Jasiński R. (2002) [2+3] Cycloaddition reactions of conjugated nitroalkenes to nitrones. Wiad. Chem., 56, 829-854.

2 Barański A., Jasiński R., Cholewka E. (2011) Krzemo i nitroolefiny w reakcjach [4+2]- $\pi$ elektronowych cykloaddycji, in. Kowalski Z. (Ed.) Postępy w inżynierii i technologii chemicznej, Cracov University of Technology, Cracow, 7-23.

3 Yakura T., Nakazawa M., Takino T., Ikeda M. (1992) Stereochemistry of 1,3-Dipolar Cycloadditions of Nitrones with E-1- Alkyl-2-nitroethenes. Chem. Pharm. Bull., 40, 2014-2018.

4 Jasiński R., Barański A. (2006) Mechanistic aspects on the [2+3] cycloaddition of Z-C,Ndiphenylnitrone with trans-1-nitropropene-1 and trans-3,3,3-trichloro-1-nitropropene-1. Polish J. Chem., 80, 1493-1502.

5 Jasiński R., Kwiatkowska M., Barański A. (2006) Unexpected results of 3-nitropropene-1 [2+3] cycloaddition to C,C,N-triphenylnitrone. Chem. Heterocyclic Cmpd., 42, 1334-1337.

6 Jasiński R. (2004) PhD Thesis, Cracow University of Technology.

7 Padwa A., Fisera L., Koehler K.F., Rodriquez A., Wong G.S.K. (1984) Regioselectivity associated with the 1,3-dipolar cycloaddition of nitrones with electron-deficient dipolarophiles. $J$. Org. Chem., 49, 276-281.

8 Pérez, P.; Domingo, L.R.; Aizman, A.; Contreras, R. (2007) The Electrophilicity Index in Organic Chemistry, in Toro-Labbe, A. (Ed.) Theoretical Aspects of Chemical Reactivity; Elsevier, Amsterdam, Vol. 19, 139-201 and references cited therein.

9 Chattaraj, P. K.; Giri. G.; Duley S. (2011) Update 2 of: Electrophilicity Index. Chem. Rev., 111, PR43-PR75 and references cited therein.

10 Parr R. G., Yang W. (1989) Density Functional Theory of Atoms and Molecules, Oxford University, New York.

11 Perez P., Domingo L.R., Aurell M.J, Contreras R. (2003) Quantitative characterization of the global electrophilicity pattern of some reagents involved in 1,3-dipolar cycloaddition reactions. Tetrahedron, 59, 3117-3125.

12 Frisch, M. J.; Trucks, G. W.; Schlegel, H. B.; Scuseria, G. E.; Robb, M. A.; Cheeseman, J. R.; Montgomery, J. A.; Vreven, T. Jr.; Kudin, K. N.; Burant, J. C.; Millam, J. M.; Iyengar, S. S.; Tomasi, J.; Barone, V.; Mennucci, B.; Cossi, M.; Scalmani, G.; Rega, N.; Petersson, G. A.; Nakatsuji, H.; Hada, M.; Ehara, M.; Toyota, K.; Fukuda, R.; Hasegawa, J.; Ishida, M.; Nakajima, Y.; Honda, O.; Kitao, O.; Nakai, H.; Klene, M.; Li, X.; Knox, J. E.; Hratchian, H. P.; Cross, J. B.; Adamo, C.; Jaramillo, J.; Gomperts, R.; Stratmann, R. E.; Yazyev, O.; Austin, A. J.; Cammi, R.; Pomelli, C.; Ochterski, J. W.; Ayala, P. Y.; Morokuma, K.; Voth, G. A.; Salvador, P.; Dannenberg, J. J.; Zakrzewski, V. G.; Dapprich, S.; Daniels, A. D.; Strain, M. C.; Farkas, M. C.; Malick, D. K.; Rabuck, A. D.; Raghavachari, K.; Foresman, J. B.; Ortiz, J. V.; Cui, Q.; Baboul, A. G.; Clifford, S.; Cioslowski, J.; Stefanov, B. B.; Liu, G.; Liashenko, A.; Piskorz, P.; Komaromi, I., Martin, R. L., Fox D. J., Keith T., Al-Laham M. A., Peng C. Y., Nanayakkara A., Challacombe M., Gill, P. M. W., Johnson, B., Chen, W., Wong, M. W., Gonzalez, C., Pople, J. A. (2009) Gaussian 09. Gaussian, Inc., Wallingford CT and references cited therein. 
13 Perez P., Domingo L.R., Duque-Norena M., Chamorro E. (2009) A condensed-to-atom nucleophilicity index. An application to the director effects on the electrophilic aromatic substitutions. J. Mol. Struct. (TheoChem), 895, 86-91.

14. Aizman A., Contreras R. (2004) Back to basics: modern reactivity concepts within the HMO theory framework. J. Chil. Chem. Soc., 49, 107-111. 